\title{
The relationship between retinol-binding protein 4 and apolipoprotein B-containing lipoproteins is attenuated in patients with very high serum triglycerides: A pilot study
}

\author{
Georgios A. Christou, ${ }^{1}$ Constantinos C. Tellis, ${ }^{2}$ Moses S. Elisaf, ${ }^{3}$ \\ Alexandros D. Tselepis, ${ }^{2}$ Dimitrios N. Kiortsis ${ }^{1}$ \\ ${ }^{1}$ Laboratory of Physiology, Medical School, '2Laboratory of Biochemistry, Department of Chemistry, ${ }^{3}$ Department of \\ Internal Medicine, Medical School, University of loannina, loannina, Greece
}

\begin{abstract}
OBJECTIVE: The investigation of the association between retinol-binding protein $4\left(\mathrm{RBP}_{4}\right)$ and lipoproteins in subjects with hypertriglyceridemia. DESIGN: Forty-six obese or overweight hypertriglyceridemic patients were studied at baseline and 20 of them underwent a hypocaloric low-fat diet for 3 months. RESULTS: Plasma $\mathbf{R B P}_{4}$ levels were positively correlated with serum triglycerides (TG) in the subgroup of patients with $\mathrm{TG}<200 \mathrm{mg} / \mathrm{dL}(\mathrm{r}=\mathbf{0 . 4 5 3}, \mathrm{p}=\mathbf{0 . 0 3 9})$ and negatively correlated with TG in patients with TG $\geq 200 \mathrm{mg} / \mathrm{dL}(\mathrm{r}=-\mathbf{0 . 4 8 7}, \mathrm{p}=0.019)$. In the subgroup with $T G<200 \mathrm{mg} / \mathrm{dL}$, subjects with circulating $\mathrm{RBP}_{4}$ above the median $46 \mathrm{mg} / \mathrm{L}$ had higher levels of intermediate density lipoprotein-cholesterol (IDL-C), low-density lipoproteincholesterol (LDL-C) and apolipoprotein B (ApoB), while these differences were absent in patients with $T G \geq 200 \mathrm{mg} / \mathrm{dL}$. The associations of percentage changes of circulating $\mathrm{RBP}_{4}$ with the percentage changes of LDL-C, very low-density lipoprotein-cholesterol (VLDL-C) and $A p o B$ were positive after the first month and 3 months of diet for patients with baseline TG $<200 \mathrm{mg} / \mathbf{d L}$, while no correlations existed for patients with TG $\geq \mathbf{2 0 0} \mathbf{~ m g} / \mathbf{d L}$. CONCLUSIONS: The positive association between circulating $\mathrm{RBP}_{4}$ and $\mathrm{ApoB}$-containing lipoproteins in a steady metabolic state, as well as during a hypocaloric diet, appears to be attenuated in patients with very high TG.
\end{abstract}

Key words: Apolipoprotein B, Diet, Obesity, Retinol-binding protein 4, Triglycerides

\section{INTRODUCTION}

Retinol-binding protein $4\left(\mathrm{RBP}_{4}\right)$, a transport protein

Address for correspondence:

Dimitrios N Kiortsis, MD, PhD, Professor of Physiology, Laboratory of Physiology, Medical School, University

of Ioannina, 45110 Ioannina, Greece; Tel.: +30 2651007551,

Fax: +30 2651007850, E-mail: dkiorts@cc.uoi.gr

Received: 05-12-2015, Accepted: 22-02-2016 for vitamin A, is synthesized mainly by the hepatocytes and secondly by the adipose tissue. ${ }^{1}$ Plasma $\mathrm{RBP}_{4}$ levels are upregulated in insulin resistant states associated with obesity, while $\mathrm{RBP}_{4}$ also induces insulin resistance. ${ }^{1,2}$ Furthermore, elevated circulating $\mathrm{RBP}_{4}$ has been associated with the development of cardiovascular disease. ${ }^{3-6}$ Circulating $\mathrm{RBP}_{4}$ has been shown to be positively correlated with serum triglycerides (TG) 
and low-density lipoprotein-cholesterol (LDL-C) and negatively with high-density lipoprotein-cholesterol (HDL-C). ${ }^{1,7}$ Among these associations the strongest and the most consistently reported has been the association with TG. ${ }^{1,8}$ Moreover, serum $\mathrm{RBP}_{4}$ levels have been shown to increase TG in mice. ${ }^{9}$ These data indicate that $\mathrm{RBP}_{4}$ are possibly associated with TG metabolism. In the present study we investigated the association of $\mathrm{RBP}_{4}$ with various lipid parameters in subjects with obesity-related hypertriglyceridemia at baseline and during dietary intervention.

\section{MATERIALS AND METHODS}

\section{Subjects}

In the present study 46 subjects were recruited. They attended the obesity outpatient clinic of the University of Ioannina, Greece. Inclusion criteria were: body mass index $(\mathrm{BMI}) \geq 27 \mathrm{Kg} / \mathrm{m}^{2}$ and hypertriglyceridemia ( $\mathrm{TG} \geq 150 \mathrm{mg} / \mathrm{dL}$ ). Exclusion criteria were: age less than 18 years old, pregnancy, breastfeeding, kidney disease, liver disease, gastrointestinal disease, malignancy, any endocrine disorder or metabolic disease other than obesity or type 2 diabetes mellitus (T2DM), alteration of body weight (BW) by up to $5 \%$ of the initial BW during the last 3 months, any state of stress or systemic inflammation, taking any one of the following drugs within 3 weeks before the start of the study: hypolipidemic agents, antidiabetics, drugs for weight loss, $\beta$-blockers or thiazides. Diagnosis of T2DM was reasonably excluded by asking medical history and assessing the values of fasting serum glucose and HbAlc.

Among the total population, 20 participants underwent a hypocaloric low-fat diet for 3 months. A dietician, taking into account each patient's basal energy requirements and on an estimation of the subject's typical activity level, prescribed an individualized low-fat diet promoting a 500 to $1000 \mathrm{kcal}$ reduction in daily energy intake. The administered diets consisted of a mean of $1471 \pm 382 \mathrm{kcal} /$ day (ranging from 1085 to $2000 \mathrm{kcal} /$ day depending on the initial $\mathrm{BW})$. The daily distribution of nutrients during the study was as follows: carbohydrates $52.4 \pm 3.5 \%$, fat $27.8 \pm 2.6 \%$ (monounsaturated $15.4 \pm 1.7 \%$, polyunsaturated $7.3 \pm 1.2 \%$ and saturated fatty acids $5.1 \pm 1.0 \%$ ) and protein $19.8 \pm 1.2 \%$. There were no differences in diet composition between the study groups. At the end of the 3-month period, the patients were consuming significantly less carbohydrates and saturated fatty acids as well as more monounsaturated fatty acids and n-3 polyunsaturated fatty acids compared with their baseline diet. All patients were asked to attend the clinic monthly during the treatment in order to assess diet compliance.

Anthropometric measurements and collection of venous blood samples, after an overnight fast of at least $12 \mathrm{~h}$, were performed at baseline, after 1 month and after 3 months of treatment. Plasma samples were stored at $-80{ }^{\circ} \mathrm{C}$ until analysis.

\section{Measurement of $\boldsymbol{R B P}_{4}$}

Plasma $\mathrm{RBP}_{4}$ was analyzed using a commercially available enzyme-linked immunosorbent assay (ELISA) kit (ALPCO DIAGNOSTICS), following the manufacturer's instructions, as previously described. ${ }^{10}$

\section{LDL subclass analysis}

LDL subclass analysis was performed electrophoretically by use of high-resolution 3\% polyacrylamide gel tubes and the Lipoprint LDL System (Quantimetrix, Redondo Beach, CA), as we have previously described. ${ }^{10}$ After electrophoresis, very low-density lipoprotein (VLDL) remained at the origin [retention factor $(\mathrm{Rf})=0.0]$, HDL migrated to the front $(\mathrm{Rf}=1.0)$. In between, several bands can be detected: MID bands $\mathrm{C}, \mathrm{B}$, and $\mathrm{A}$, which correspond mainly to intermediate-density lipoprotein (IDL), as well as up to 7 LDL bands. The LDL-1 and LDL-2 bands correspond to large buoyant LDL particles, whereas bands LDL-3 to LDL-7 correspond to sdLDL particles. A detailed description of the methods used for the measurement of LDL subclasses can be found in an expert consensus document of the "European panel on LDL subclasses". ${ }^{11}$

\section{Routine biochemical measurements}

Total serum cholesterol (TC), HDL-C and TG were measured by enzymatic methods, as previously described. ${ }^{10,12}$ Non-HDL-cholesterol was calculated as TC-HDL-C. Serum apolipoprotein (Apo) A-I and ApoB levels were measured with a Behring Holding $\mathrm{GmbH}$ analyzer (Liederbach, Germany).

Serum Creatinine $(\mathrm{Cr})$ levels were determined by 
standard laboratory methods. The Modification of Diet in Renal Disease (MDRD) formula was used for the estimation of glomerular filtration rate (eGFR). ${ }^{13}$ Body surface area (BSA) was calculated by body weight (BW) and height $(\mathrm{H})$ using the Du Bois formula: BSA $=0.007184 \times \mathrm{BW}^{0.425} \times \mathrm{H}^{0.725}\left(\mathrm{BSA}\right.$ is in $\mathrm{m}^{2}$, BW is in $\mathrm{kg}$, and $\mathrm{H}$ is in $\mathrm{cm}) .{ }^{14}$

\section{Statistical analysis}

All statistical analyses were performed using the SPSS 16.0 statistical package for Windows (SPSS Inc., 1989-2007). The Kolmogorov-Smirnov test was used to verify the normality of the distributions of the parameters of interest. Normally distributed data were expressed as means \pm SD. Parameters with skewed distribution were reported as median (range). The paired t-test, independent t-test and Pearson's correlation analysis were performed for normally distributed parameters, whereas the Mann-Whitney U test and Spearman's correlation analysis were performed for non-normally distributed parameters. Linear regression analysis was used for the assessment of the relationship between circulating $\mathrm{RBP}_{4}$ and lipid parameters after adjustment for gender and cGFR. A two-tailed $p$ value $<0.05$ was considered significant.

\section{RESULTS}

\section{Baseline}

Participants were $50 \pm 14$ years old ( 24 males and 22 females) and their BMI was $36.5 \pm 7.3 \mathrm{Kg} / \mathrm{m}^{2}$. Plasma $\mathrm{RBP}_{4}$ levels were higher in males compared with females $(54.7 \pm 14.2 \mathrm{mg} / \mathrm{L}$ vs $42.2 \pm 13.6 \mathrm{mg} / \mathrm{L}$, $\mathrm{p}=0.005$ ). Circulating $\mathrm{RBP}_{4}$ was positively correlated with $\mathrm{Cr}(\mathrm{r}=0.367, \mathrm{p}=0.014)$. Although circulating $\mathrm{RBP}_{4}$ was not correlated with eGFR, it was negatively correlated with corrected GFR for BSA (cGFR) $(\mathrm{r}=$ 0.311, $\mathrm{p}=0.040$ ).

Plasma $\mathrm{RBP}_{4}$ levels were not correlated with $\mathrm{TG}$ in all patients. Circulating $\mathrm{RBP}_{4}$ was positively correlated with TG in the subgroup of patients with TG $<200 \mathrm{mg} / \mathrm{dL}(\mathrm{r}=0.453, \mathrm{p}=0.039)$ and negatively correlated with TG in the subgroup of patients with TG $\geq 200 \mathrm{mg} / \mathrm{dL}(\mathrm{r}=-0.487, \mathrm{p}=0.019)$.

Table 1 shows the values of circulating lipoproteins in the subgroups of patients with plasma $\mathrm{RBP}_{4}$ levels below or above the median $46 \mathrm{mg} / \mathrm{L}$ in all patients as well as in subjects with TG $<$ or $\geq 200 \mathrm{mg} / \mathrm{dL}$. In all patients, subjects with circulating $\mathrm{RBP}_{4}$ above the median $46 \mathrm{mg} / \mathrm{L}$ had higher levels of IDL-C, LDLC, nonHDL-C and ApoB and lower levels of ApoE compared with subjects with circulating $\mathrm{RBP}_{4}$ below $46 \mathrm{mg} / \mathrm{L}$. There was a tendency for higher levels of $\mathrm{TC}$ and VLDL-C in subjects with circulating $\mathrm{RBP}_{4}$ above $46 \mathrm{mg} / \mathrm{L}$.

In the subgroup of patients with $\mathrm{TG}<200 \mathrm{mg} /$ $\mathrm{dL}$, subjects with circulating $\mathrm{RBP}_{4}$ above $46 \mathrm{mg} / \mathrm{L}$ had higher levels of IDL-C, LDL-C and nonHDL-C and lower levels of $\mathrm{Lp}$ (a) compared with subjects with circulating $\mathrm{RBP}_{4}$ below $46 \mathrm{mg} / \mathrm{L}$. There was a tendency for higher levels of ApoB in subjects with circulating $\mathrm{RBP}_{4}$ above $46 \mathrm{mg} / \mathrm{L}$. Linear regression analysis showed that plasma $\mathrm{RBP}_{4}$ levels were positively correlated with VLDL-C after adjustment for gender and $\mathrm{cGFR}(\beta=1.779, \mathrm{p}=0.013)$.

In the subgroup of patients with $\mathrm{TG} \geq 200 \mathrm{mg} / \mathrm{dL}$, subjects with serum $\mathrm{RBP}_{4}$ levels above $46 \mathrm{mg} / \mathrm{L}$ had lower levels of TG, sdLDL-C and ApoE compared with subjects with circulating $\mathrm{RBP}_{4}$ below $46 \mathrm{mg} / \mathrm{L}$.

\section{Dietary treatment}

BMI was significantly decreased from baseline $\left(36.2 \pm 5.7 \mathrm{Kg} / \mathrm{m}^{2}\right)$ after first month $\left(35.7 \pm 4.6 \mathrm{Kg} / \mathrm{m}^{2}\right.$, $\mathrm{p}<0.001)$, as well as after 3 months of $\operatorname{diet}(34.9 \pm 5.1$ $\left.\mathrm{Kg} / \mathrm{m}^{2}, \mathrm{p}<0.001\right)$. Circulating $\mathrm{RBP}_{4}$ decreased after 3 months of diet (from $51.9 \pm 13.8$ to $45.7 \pm 14.7$, $\mathrm{p}=0.03$ ). Table 2 shows the associations between the percentage change of plasma $\mathrm{RBP}_{4}$ levels after 1 month of treatment and the percentage changes of IDL-C, LDL-C, VLDL-C, sdLDL-C and ApoB in the total of subjects who underwent dietary treatment and in the subgroups of patients with baseline TG above or below $200 \mathrm{mg} / \mathrm{dL}$. Table 3 shows similar data to Table 2 regarding the 3 months of diet. The associations of percentage changes of circulating $\mathrm{RBP}_{4}$ with the percentage changes of IDL-C, LDL$\mathrm{C}$, VLDL-C, sdLDL-C and ApoB were positive over the first month and 3 months of diet for patients with baseline $\mathrm{TG}<200 \mathrm{mg} / \mathrm{dL}$, while no correlations existed for patients with baseline $\mathrm{TG} \geq 200 \mathrm{mg} / \mathrm{dL}$, except for IDL-C during first month and sdLDL-C for 3 months. 
Table 1. The comparison of lipid parameters between subjects with circulating $\mathrm{RBP}_{4}$ below and above the median $46 \mathrm{mg} / \mathrm{L}$, in all patients and in the subgroups with serum triglycerides $(\mathrm{TG})<$ or $\geq 200 \mathrm{mg} / \mathrm{dL}$

\begin{tabular}{|c|c|c|c|c|c|c|c|c|c|}
\hline & \multicolumn{3}{|c|}{ All patients $(n=46)$} & \multicolumn{3}{|c|}{$\mathrm{TG}<200 \mathrm{mg} / \mathrm{dL}(\mathrm{n}=22)$} & \multicolumn{3}{|c|}{$T G \geq 200 \mathrm{mg} / \mathrm{dL}(\mathrm{n}=24)$} \\
\hline & $\begin{array}{c}\mathrm{RBP}_{4} \\
<46 \mathrm{mg} / \mathrm{L} \\
(\mathrm{n}=22)\end{array}$ & $\begin{array}{c}\mathrm{RBP}_{4} \\
\geq 46 \mathrm{mg} / \mathrm{L} \\
(\mathrm{n}=24)\end{array}$ & $\mathbf{p}$ & $\begin{array}{c}\mathrm{RBP}_{4} \\
<46 \mathrm{mg} / \mathrm{L} \\
(\mathrm{n}=12)\end{array}$ & $\begin{array}{c}\mathrm{RBP}_{4} \\
\geq 46 \mathrm{mg} / \mathrm{L} \\
(\mathrm{n}=10)\end{array}$ & p & $\begin{array}{c}\mathrm{RBP}_{4} \\
<46 \mathrm{mg} / \mathrm{L} \\
(\mathrm{n}=10)\end{array}$ & $\begin{array}{c}\mathrm{RBP}_{4} \\
\geq 46 \mathrm{mg} / \mathrm{L} \\
(\mathrm{n}=14)\end{array}$ & p \\
\hline $\mathrm{TC}(\mathrm{mg} / \mathrm{dL})$ & $239 \pm 28$ & $259 \pm 39$ & 0.059 & $235 \pm 27$ & $256 \pm 26$ & 0.135 & $243 \pm 30$ & $260 \pm 46$ & 0,483 \\
\hline $\mathrm{TG}(\mathrm{mg} / \mathrm{dL})$ & $235 \pm 100$ & $227 \pm 56$ & 0.697 & $162 \pm 18$ & $171 \pm 21$ & 0.473 & $323 \pm 86$ & $262 \pm 41$ & 0.049 \\
\hline HDL-C (mg/dL) & $45 \pm 9$ & $45 \pm 7$ & 0.688 & $47 \pm 9$ & $44 \pm 7$ & 0,734 & $41 \pm 7$ & $45 \pm 7$ & 0,343 \\
\hline IDL-C (mg/dL) & $51 \pm 10$ & $62 \pm 14$ & 0.010 & $55 \pm 10$ & $69 \pm 12$ & 0.043 & $48 \pm 9$ & $57 \pm 13$ & 0.180 \\
\hline LDL-C (mg/dL) & $132 \pm 15$ & $149 \pm 28$ & 0.028 & $127 \pm 14$ & $154 \pm 21$ & 0.043 & $136 \pm 16$ & $147 \pm 32$ & 0.582 \\
\hline VLDL-C (mg/dL) & $52 \pm 10$ & $59 \pm 12$ & 0.102 & $50 \pm 4$ & $54 \pm 6$ & 0.282 & $54 \pm 12$ & $62 \pm 14$ & 0.346 \\
\hline sdLDL-C (mg/dL) & $19 \pm 11$ & $14 \pm 8$ & 0.147 & $10 \pm 7$ & $10 \pm 8$ & 0.950 & $25 \pm 10$ & $16 \pm 7$ & 0.025 \\
\hline nonHDL-C (mg/dL) & $185 \pm 23$ & $208 \pm 34$ & 0.037 & $188 \pm 21$ & $212 \pm 23$ & 0.031 & $202 \pm 26$ & $215 \pm 41$ & 0.648 \\
\hline ApoA-I (mg/dL) & $141 \pm 17$ & $137 \pm 16$ & 0.320 & $141 \pm 16$ & $132 \pm 15$ & 0.310 & $142 \pm 19$ & $139 \pm 17$ & 0.693 \\
\hline ApoB (mg/dL) & $114 \pm 24$ & $131 \pm 31$ & 0.049 & $113 \pm 19$ & $127 \pm 18$ & 0.075 & $115 \pm 30$ & $134 \pm 38$ & 0.483 \\
\hline ApoE (mg/L) & $63 \pm 21$ & $51 \pm 11$ & 0.037 & $50 \pm 11$ & $47 \pm 11$ & 0.456 & $76 \pm 22$ & $54 \pm 10$ & 0.022 \\
\hline $\mathrm{Lp}(\mathrm{a})(\mathrm{mg} / \mathrm{dL})$ & $\begin{array}{c}8.40 \\
(2.44-69.90)\end{array}$ & $\begin{array}{c}4.45 \\
2.44-32.00)\end{array}$ & 0.257 & $\begin{array}{c}8.80 \\
(2.44-69.90)\end{array}$ & $\begin{array}{c}4.70 \\
(2.44-7.70)\end{array}$ & 0.042 & $\begin{array}{c}2.97 \\
(2.44-50.60)\end{array}$ & $\begin{array}{c}4.20 \\
(2.44-32.00)\end{array}$ & 0.661 \\
\hline
\end{tabular}

Data are means \pm SD for normally distributed variables or median (range) for non-normal variables.

TC: total cholesterol; TG: triglycerides; HDL-C: high density lipoprotein-cholesterol, IDL-C: intermediate-density lipoproteincholesterol; LDL-C: low density lipoprotein-cholesterol; VLDL-C: very low density lipoprotein-cholesterol; sdLDL-C: small dense LDL-cholesterol; nonHDL-C: non-HDL-cholesterol; ApoA-I: apolipoprotein A-I; ApoB: apolipoprotein B; ApoE: apolipoprotein E; $\mathrm{Lp}(\mathrm{a})$ : lipoprotein(a)

The $\mathrm{p}$ value refers to the comparison of the lipid parameters between subjects with serum RBP4 levels below and above $46 \mathrm{mg} / \mathrm{L}$, after performing the independent t-test for normally distributed parameters and Mann-Whitney U test for non-normally distributed parameters.

Table 2. Correlations between percentage change of plasma RBP4 levels over one month of diet and percentage changes of TG, LDL-C, IDL-C, VLDL-C, sdLDL-C and ApoB

\begin{tabular}{|c|c|c|c|c|c|c|}
\hline & \multicolumn{2}{|c|}{ All patients $(n=20)$} & \multicolumn{2}{|c|}{$T G<200 \mathrm{mg} / \mathrm{dL}(\mathrm{n}=10)$} & \multicolumn{2}{|c|}{$T G \geq 200 \mathrm{mg} / \mathrm{dL}(\mathrm{n}=10)$} \\
\hline & $\mathbf{r}$ & $\mathbf{p}$ & $\mathbf{r}$ & p & $\mathbf{r}$ & p \\
\hline$\%$ change of IDL-C & 0.296 & 0.265 & 0.500 & 0.207 & 0.095 & 0.823 \\
\hline$\%$ change of LDL-C & 0.290 & 0.276 & 0.786 & 0.021 & -0.685 & 0.061 \\
\hline$\%$ change of VLDL-C & 0.441 & 0.087 & 0.976 & $<0.001$ & -0.238 & 0.570 \\
\hline$\%$ change of sdLDL-C & 0.447 & 0.083 & 0.898 & 0.002 & -0.024 & 0.955 \\
\hline$\%$ change of ApoB & 0.493 & 0.045 & 0.667 & 0.049 & 0.110 & 0.796 \\
\hline
\end{tabular}

TG: triglycerides; IDL-C: intermediate-density lipoprotein-cholesterol; LDL-C: low density lipoprotein-cholesterol; VLDL-C: very low density lipoprotein-cholesterol; sdLDL-C: small dense LDL-cholesterol; ApoB: apolipoprotein B.

\section{DISCUSSION}

The present study showed that the association between circulating $\mathrm{RBP}_{4}$ and TG was characterized by a biphasic mode, being positive for $\mathrm{TG}<200 \mathrm{mg} / \mathrm{dL}$ and negative for $\mathrm{TG} \geq 200 \mathrm{mg} / \mathrm{dL}$. Moreover, the positive association between $\mathrm{RBP}_{4}$ and ApoB-containing lipoproteins in a steady metabolic state, as well as during the hypocaloric low-fat diet, was found to be attenuated in subjects with $\mathrm{TG} \geq 200 \mathrm{mg} / \mathrm{dL}$.

\section{The relationship between $\boldsymbol{R B P}_{4}$ and ApoB-containing lipoproteins}

The current study demonstrated that circulating $\mathrm{RBP}_{4}$ was positively correlated with serum levels of the ApoB-containing lipoproteins LDL-C, IDL-C and 
Table 3. Correlations between percentage change of plasma RBP4 levels over 3 months of diet and percentage changes of TG, LDL-C, IDLC, VLDL-C, sdLDL-C and ApoB

\begin{tabular}{|c|c|c|c|c|c|c|}
\hline & \multicolumn{2}{|c|}{ All patients $(n=20)$} & \multicolumn{2}{|c|}{ TG $<200 \mathrm{mg} / \mathrm{dL}(\mathrm{n}=10)$} & \multicolumn{2}{|c|}{$T G \geq 200 \mathrm{mg} / \mathrm{dL}(\mathrm{n}=10)$} \\
\hline & $\mathbf{r}$ & p & $\mathbf{r}$ & $\mathbf{p}$ & $\mathbf{r}$ & $\mathbf{p}$ \\
\hline$\%$ change of IDL-C & -0.117 & 0.654 & 0.783 & 0.013 & -0.429 & 0.289 \\
\hline$\%$ change of LDL-C & 0.708 & 0.001 & 0.967 & $<0.001$ & 0.619 & 0.102 \\
\hline$\%$ change of VLDL-C & 0.570 & 0.017 & 0.760 & 0.018 & -0.190 & 0.651 \\
\hline$\%$ change of sdLDL-C & 0.872 & $<0.001$ & 0.908 & 0.001 & 0.790 & 0.020 \\
\hline$\%$ change of ApoB & 0.635 & 0.005 & 0.782 & 0.008 & 0.405 & 0.320 \\
\hline
\end{tabular}

TG: triglycerides; IDL-C: intermediate-density lipoprotein-cholesterol; LDL-C: low density lipoprotein-cholesterol; VLDL-C: very low density lipoprotein-cholesterol; sdLDL-C: small dense LDL-cholesterol; ApoB: apolipoprotein B.

VLDL-C. Importantly, this relationship was shown not only at baseline but also during a hypocaloric low-fat diet. Indeed, our study group has demonstrated that circulating $\mathrm{RBP}_{4}$ is possibly associated more consistently and strongly with the metabolism of the ApoB-containing lipoproteins than the metabolism of the ApoA-I-containing lipoprotein HDL. ${ }^{1,10} \mathrm{RBP}_{4}$ has been found to induce not only the enhancement of hepatic production of ApoB-containing lipoproteins but also the decrease in catabolism of ApoB-containing lipoproteins through the downregulation of the LDL receptor. ${ }^{15}$ To our knowledge, the association between circulating $\mathrm{RBP}_{4}$ and IDL-C has not previously been investigated.

\section{The relationship between $R_{B} P_{4}$ and TG in patients with $T G<200 \mathrm{mg} / \mathrm{dL}$}

The positive association between circulating $\mathrm{RBP}_{4}$ and TG has consistently been reported in studies investigating subjects with variable TG levels, including normal as well as high TG levels. ${ }^{7,8}$ This relationship is possibly causal since treatment with RNA oligonucleotide against $\mathrm{RBP}_{4}$ was shown to reduce TG levels in mice. ${ }^{9}$ Vergès et al found that circulating $\mathrm{RBP}_{4}$ in patients with T2DM was negatively correlated with indirect VLDL-apoB fractional catabolic rate (FCR), which represents the VLDL delipidation toward IDL, while there was no significant association with direct VLDL-apoB FCR, which reflects the direct VLDL removal from plasma through receptor-mediated particle uptake. ${ }^{16}$

\section{The relationship of $\mathrm{RBP}_{4}$ with lipoproteins in patients with $T G \geq 200 \mathrm{mg} / \mathrm{dL}$}

The negative association between circulating $\mathrm{RBP}_{4}$ and TG in patients with $\mathrm{TG} \geq 200 \mathrm{mg} / \mathrm{dL}$ of the current study was accompanied by the dissociation between circulating $\mathrm{RBP}_{4}$ and ApoB-containing lipoproteins. $\mathrm{A}$ possible explanation for these data is the downregulation of plasma $\mathrm{RBP}_{4}$ levels in patients with $\mathrm{TG} \geq 200$ $\mathrm{mg} / \mathrm{dL}$. Further studies are needed to confirm these findings and elucidate the underlying mechanisms. The dissociation between circulating $\mathrm{RBP}_{4}$ and $\mathrm{ApoB}$ containing lipoproteins in patients with considerable hypertriglyceridemia that was found in the present study implies that the adverse impact of $\mathrm{RBP}_{4}$ on lipoprotein metabolism may be important only in patients without considerable hypertriglyceridemia. In this context, it is prudent to evaluate the effects of $\mathrm{RBP}_{4}$ on lipoprotein metabolism only in patients without considerable hypertriglyceridemia, at least in initial studies.

The negative relationship between circulating $\mathrm{RBP}_{4}$ and serum ApoE levels in patients with TG $\geq 200 \mathrm{mg} / \mathrm{dL}$ of the current study may be explained by the high serum levels of ApoE, which is carried by remnants of triglyceride-rich lipoproteins in subjects with hypertriglyceridemia. ${ }^{17}$ The relationship between $\mathrm{RBP}_{4}$ and $\mathrm{ApoE}$ has not been investigated in any previous study.

\section{Study strengths and limitations}

Strengths of this study include the investigation for the first time of the relationship of $\mathrm{RBP}_{4}$ with lipoproteins in patients who had exclusively hypertriglyceridemia and not in mixed populations with variable TG levels. Secondly, taking into account the many factors that influence circulating $\mathrm{RBP}_{4}$, including renal or liver impairment and drugs affect- 
ing metabolism, the present study excluded patients with all these conditions. ${ }^{1}$ However, an important limitation of the majority of studies investigating $\mathrm{RBP}_{4}$ was that they did not take into account all these factors. Thirdly, the current study applied a direct measurement of all ApoB-containing lipoproteins through lipoprotein electrophoresis. However, most of the studies investigating the relationship between $\mathrm{RBP}_{4}$ and LDL-C assessed LDL-C by its indirect calculation using the Friedewald equation [LDL-C $=\mathrm{TC}-($ HDL $-\mathrm{C}+\mathrm{TG} / 5)]$, which is less accurate than the direct measurement of LDL-C, especially in subjects with considerable hypertriglyceridemia, as is the case in the present study. ${ }^{18}$ Moreover, LDL-C calculated through the Friedewald equation represents a crude estimation of the sum of directly measured LDL-C and IDL-C and thus it is not a highly accurate estimation of true LDL-C.

The results of the present study should be interpreted in light of some limitations. Firstly, the number of patients was not large enough, thus decreasing the statistical power of the study to detect significant associations of circulating $\mathrm{RBP}_{4}$ with serum lipoprotein levels. Therefore, taking into account the small number of study participants, firm conclusions cannot be drawn regarding the relationship between circulating $\mathrm{RBP}_{4}$ and ApoB-containing lipoproteins in subjects with hypertriglyceridemia. Secondly, the relationships between $\mathrm{RBP}_{4}$ and lipoproteins that were found in the current study cannot confirm the existence of causal mechanisms underlying these associations.

In conclusion, the present study showed that circulating $\mathrm{RBP}_{4}$ was positively correlated with serum levels of ApoB-containing lipoproteins in a steady metabolic state, as well as during a hypocaloric low-fat diet in overweight or obese patients with hypertriglyceridemia. This relationship appears to be attenuated in patients with $T G \geq 200 \mathrm{mg} / \mathrm{dL}$. Further well designed studies with a greater number of patients are needed to confirm these results and elucidate the underlying mechanisms.

\section{CONFLICT OF INTEREST}

The authors declare that there is no conflict of interest.

\section{REFERENCES}

1. Christou GA, Tselepis AD, Kiortsis DN, 2012 The metabolic role of retinol binding protein 4: an update. Horm Metab Res 44: 6-14.

2. Yang Q, Graham TE, Mody N, et al, 2005 Serum retinol binding protein 4 contributes to insulin resistance in obesity and type 2 diabetes. Nature 436: 356-362.

3. Sun Q, Kiernan UA, Shi L, et al, 2013 Plasma retinolbinding protein 4 (RBP4) levels and risk of coronary heart disease: a prospective analysis among women in the nurses' health study. Circulation 127: 1938-1947.

4. Lambadiari V, Kadoglou NP, Stasinos V, et al. 2014 Serum levels of retinol-binding protein-4 are associated with the presence and severity of coronary artery disease. Cardiovasc Diabetol 13: 121.

5. Liu Y, Wang D, Chen H, Xia M, 2015 Circulating retinol binding protein 4 is associated with coronary lesion severity of patients with coronary artery disease. Atherosclerosis 238: 45-51.

6. Wan K, Zhao J, Deng Y, et al, 2014 A genetic polymorphism in RBP4 is associated with coronary artery disease. Int J Mol Sci 15: 22309-22319.

7. Klöting N, Graham TE, Berndt J, et al, 2007 Serum retinol-binding protein is more highly expressed in visceral than in subcutaneous adipose tissue and is a marker of intra-abdominal fat mass. Cell Metab 6: 79-87.

8. Ingelsson E, Sundström J, Melhus H, et al, 2009 Circulating retinol-binding protein 4 , cardiovascular risk factors and prevalent cardiovascular disease in elderly. Atherosclerosis 206: 239-244.

9. Tan Y, Sun LQ, Kamal MA, Wang X, Seale JP, Qu X, 2011 Suppression of retinol-binding protein 4 with RNA oligonucleotide prevents high-fat diet-induced metabolic syndrome and non-alcoholic fatty liver disease in mice. Biochim Biophys Acta 1811: 1045-1053.

10. Christou GA, Tellis CC, Elisaf MS, Tselepis AD, Kiortsis DN, 2012 The changes in plasma retinol-binding protein 4 levels are associated with those of the apolipoprotein B-containing lipoproteins during dietary and drug treatment. Angiology 63: 67-75.

11. Mikhailidis DP, Elisaf M, Rizzo M, 2011 European panel on low density lipoprotein (LDL) subclasses: a statement on the pathophysiology, atherogenicity and clinical significance of LDL subclasses. Curr Vasc Pharmacol 9: 533-571.

12. Christou GA, Tellis KC, Elisaf MC, Tselepis AD, Kiortsis DN, 2012 High density lipoprotein is positively correlated with the changes in circulating total adiponectin and high molecular weight adiponectin during dietary and fenofibrate treatment. Hormones (Athens) 11: $178-188$.

13. Levey AS, Bosch JP, Lewis JB, Greene T, Rogers N, Roth D, 1999 A more accurate method to estimate glomerular filtration rate from serum creatinine: a new prediction 
equation. Modification of Diet in Renal Disease Study Group. Ann Intern Med 130: 461-470.

14. Du Bois D, Du Bois EF, 1989 A formula to estimate the approximate surface area if height and weight be known. 1916. Nutrition 5: 303-311.

15. Liu Y, Chen H, Wang J, Zhou W, Sun R, Xia M, 2015 Elevated retinol binding protein 4 induces apolipoprotein $\mathrm{B}$ production and associates with hypertriglyceridemia. J Clin Endocrinol Metab 100: E720-728.

16. Vergès B, Guiu B, Cercueil JP, et al, 2012 Retinolbinding protein 4 is an independent factor associated with triglycerides and a determinant of very low-density lipoprotein-apolipoprotein B100 catabolism in type 2 diabetes mellitus. Arterioscler Thromb Vasc Biol 32: 3050-3057.

17. Mahley RW, Ji ZS, 1999 Remnant lipoprotein metabolism: key pathways involving cell-surface heparan sulfate proteoglycans and apolipoprotein E. J Lipid Res 40: 1-16.

18. Friedewald WT, Levy RI, Fredrickson DS, 1972 Estimation of the concentration of low-density lipoprotein cholesterol in plasma, without use of the preparative ultracentrifuge. Clin Chem 18: 499-502. 